\title{
A DEVELOPMENT OF MULTI PURPOSE TESTING MACHINE FOR FRICTION, WEAR AND ROLLING CONTACT FATIGUE
}

\author{
GAB-SU CHOI
}

Department of Mechanical Engineering, Sun Moon University, Tangjeong-myeon Asan-si, Chungnam, 336-708 South Korea engineer008@naver.com

YOUNG-SIK PYUN, JUN-HYOUNG KIM, HAK-DOO KIM, YASUTOSHI TOMINAGA, SHIRMENDAGWA DARISUREN

Department of Mechanical Engineering, Sun Moon University, Tangjeong-myeon Asan-si,Chungnam, 336-708 South Korea

pyoun@sunmoon.ac.kr,mit026@naver.com, gamedooly@naver.com,tyasutoshi_3_22@hotmail.co.jp shirmee20@yahoo.com

\begin{abstract}
In this paper, the newly developed tribometer was introduced. Ball-on-disk, pin-on-disk, smallsized journal and thrust bearings tests on friction and wear were carried out using a newly developed tribometer which is built up according to the ASTM G99. Those friction and wear test results were compared with the friction results which were approved by Korean (KOLAS) and CSM Instruments. The comparison revealed that friction characteristics and trends of three different tribometers were similar to each other. The objective of this paper is to demonstrate the capability of the newly developed tribometer. As a result, the newly developed tribometer is capable of performing friction tests using pin-on-disk, disk-on-disk, journal and thrust bearings configurations.
\end{abstract}

Keywords: Friction test; Wear test; Pin-on-Disk test, Friction coefficients.

\section{Introduction}

One of the most important steps in reduction of $\mathrm{CO}_{2}$ emission is to reduce friction coefficient and wear of interacting surfaces in relative motion. Particularly, the requirements to surface and materials characteristics in changeable environment are going to be stricter for various industries such as automobile, airplane and high-speed railroad. Standard specimens and journal/thrust bearings were tested for measuring friction coefficient and wear using a newly developed standard tester which was built up according to the ASTM G99.

This paper describes the development of three types of multi-purpose testers (MPT) that are capable of performing various types of friction tests, small-sized journal bearing tests and ball/roller bearing tests by using interchangeable parts attached to single standing frame. These testers are able to develop up to 500, 2000 and $10000 \mathrm{~N}$ load. This 
categorization is based on load cells limits. The Pin-on-Disk test results acquired from small MPT were compared with data acquired from CSM made tribometer of client organization and with data from KOLAS, which is test certification authority in Korea. Necessary efforts were made to insure that the test conditions were identical. Also, thrust ball bearing tests were carried out on small MPT and the results were compared with previous research on the same bearings. Different disk-on-disk tests, journal bearings and Rolling Contact Friction (RCF) tests are in progress.

\section{Multi-purpose friction and wear tester design}

\subsection{Requirement of friction and wear conditions}

MPT implies that it is designed to perform various friction and wear tests such as pin-ondisk according to ASTM G99, disk-on-disk, ball-on-disk and RCF tests, as well as thrust bearing tests as shown on Fig. 1. Table 1 shows some of design conditions and

Table 1. Multi-Purpose wear and friction tester Type.

\begin{tabular}{llll}
\hline ITEM & Small TESTER & Medium TESTER & Large TESTER \\
\hline Max. Load Capacity & $500 \mathrm{~N}$ & $2,000 \mathrm{~N}$ & $10,000 \mathrm{~N}$ \\
Min. Load Capacity & $0.5 \mathrm{~N}$ & $2 \mathrm{~N}$ & $10 \mathrm{~N}$ \\
Load Cell Measurement error & $\pm 0.03 \mathrm{~N}$ & $\pm 0.3 \mathrm{~N}$ & $\pm 3 \mathrm{~N}$ \\
Rotation Speed & $1 \sim 3000 \mathrm{rpm}$ & $1 \sim 3000 \mathrm{rpm}$ & $1 \sim 3000 \mathrm{rpm}$ \\
Temp Sensor & $\mathrm{RT} \sim 150{ }^{\circ} \mathrm{C}$ & $\mathrm{RT} \sim 150^{\circ} \mathrm{C}$ & $\mathrm{RT} \sim 150{ }^{\circ} \mathrm{C}$ \\
Vibration Sensor & $0.5 \sim 50 \mathrm{Gpeak}$ & $0.5 \sim 50 \mathrm{Gpeak}$ & $0.5 \sim 50 \mathrm{Gpeak}$ \\
\hline
\end{tabular}

specifications of the newly developed MPT.

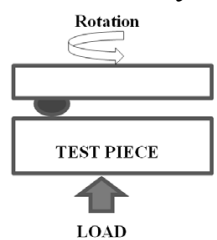

Ball on Disk (ISO7148)

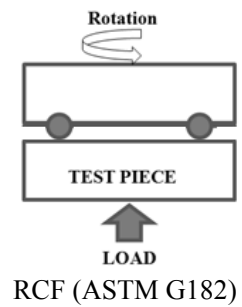

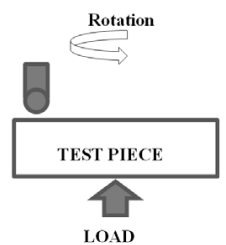

Pin on Disk (ASTM G99)

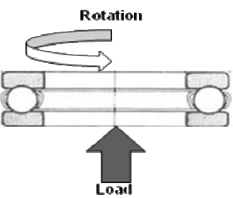

Thrust Bearing (ASTM D3702)

Fig. 1. Wear and Friction Test type

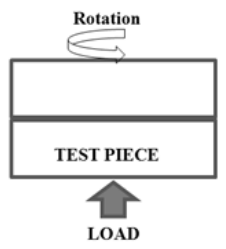

Disk on Disk (ASTM D3702-94)

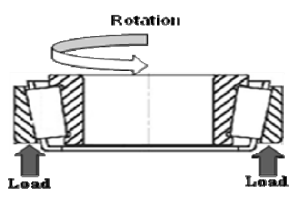

Taper roller bearing (F2591)

\subsection{Multi-purpose tester hardware design}

Fig. 2 shows small and medium size testers designed to develop up to $500 \mathrm{~N}$ and $2000 \mathrm{~N}$ load, respectively. The construction of the large, $10000 \mathrm{~N}$ tester is in progress. In order to 
make it easy to switch from one type of the test to another type each testing media (ball, pin etc.) are housed within interchangeable units (test heads) that can be easily positioned into the holding unit and mechanically fixed. Test stand designed to contain force and torque load cells, loading seesaw rig and specimen holder as well.

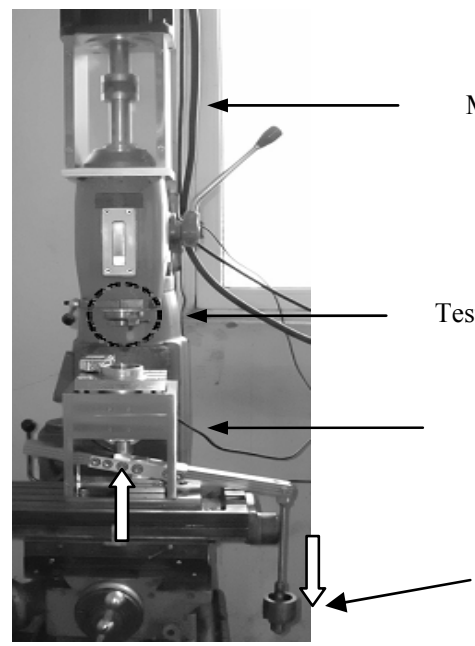

Motor Assembly

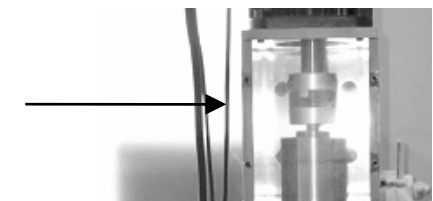

est Head and Holder

Test Stand

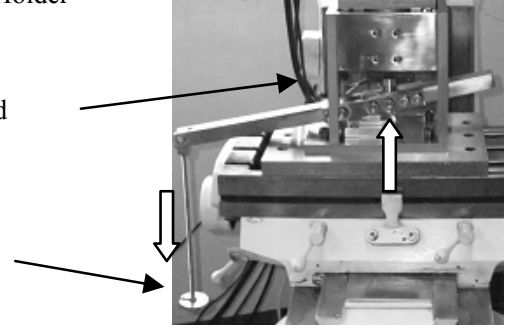

Fig. 2. (a)Multi-purpose tester, small (left) and medium (right)
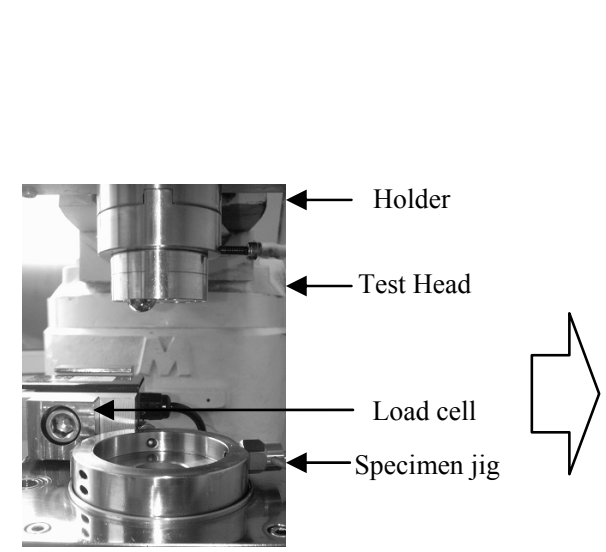

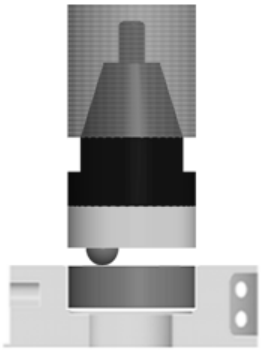

(a) Ball on Disk

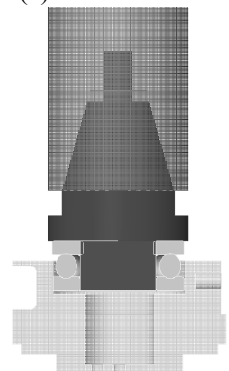

(c) Thrust ball bearing

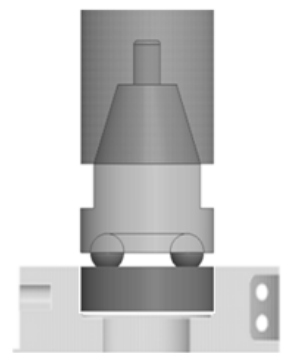

(b) $\mathrm{RCF}$

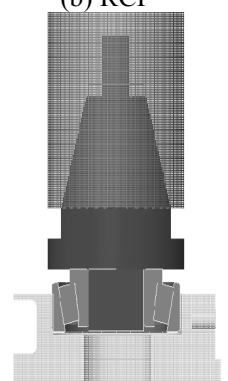

(d) Roller bearing

Fig. 3. Types of Test Heads

Fig. 3. shows disk specimen and standard thrust bearing for friction test. 

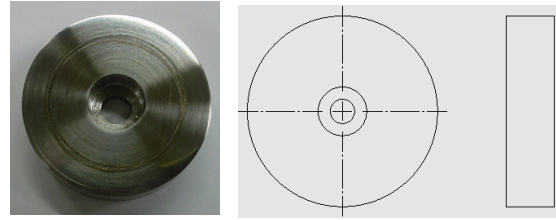

(a)Disk specimen

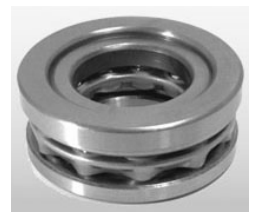

(b)Thrust bearing(51306)

Fig. 4. Specimen

\subsection{Human Machine Interface (HMI) based control system}

Initially programmable logic controller (PLC) was chosen as a control system. However, it was unable to get reliable results in real time due to delay in data extraction. Therefore, a computer equipped HMI was used for real time controlling and reading test state as shown in Fig. 5.

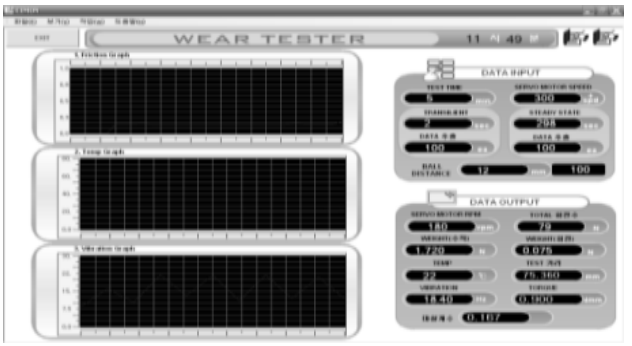

(a)HMI Design Touch Panel

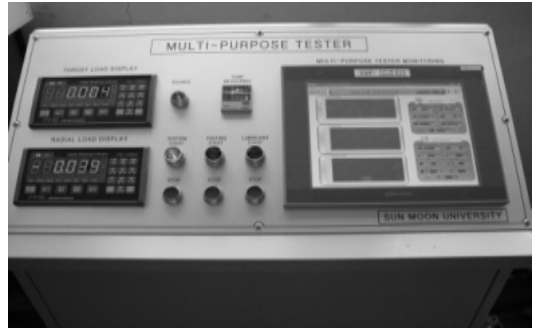

(b)Main Operator Control Panel

Fig. 5. Wear and Friction Tester Operator MHI Control System

Separate transient and steady-state displays were developed as shown in Fig. 4 (a) in order to extract reliable friction and wear data. This HMI is able to display more reliable collected data on load, rotating speed, friction torque, testing distance, temperature and vibration. This control system is able to handle various MPT simultaneously, as shown in Fig. 5.

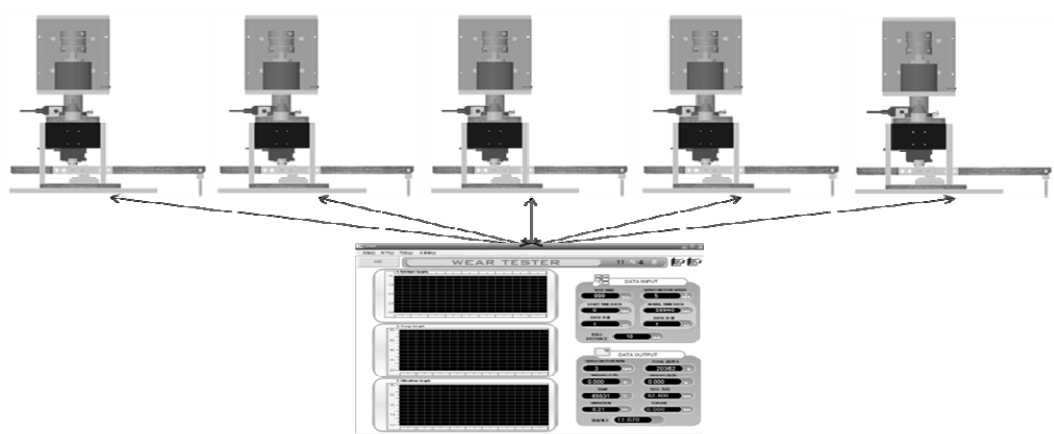

Fig. 6. HMI control system compatibility 


\section{Calibration and test of Multi-purpose Tester}

\subsection{Thrust bearing test}

The friction tests for the untreated and UNSM-treated thrust ball bearings using MPT were performed. The test results showed that the friction coefficient was reduced. Trend of the compared results confirmed that it is possible to perform friction tests on thrust bearings using MPT.

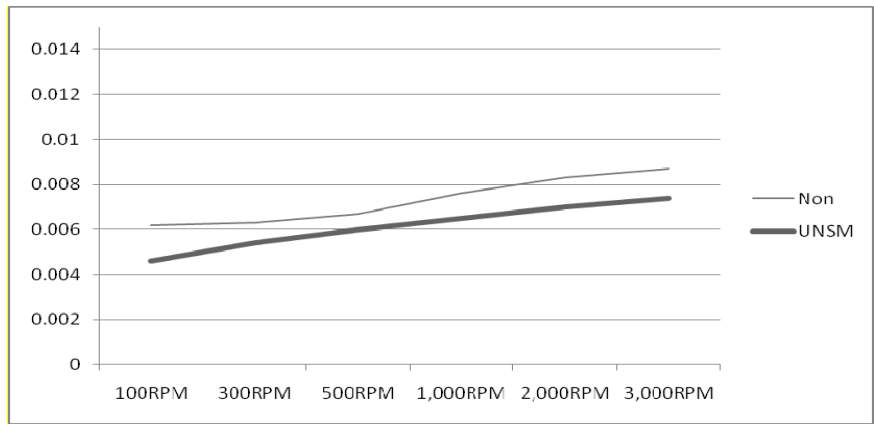

Fig. 7. Thrust Bearing Test (at $1000 \mathrm{~N}$ )

\subsection{Calibration by Pin on Disk Test}

MPT was calibrated using friction data which were received from CSM and R\&D. The test conditions were identically replicated. Beginning condition of the test was set up to read 100 data per sec at rotating speed of $100 \mathrm{rpm}$ and load of $50 \mathrm{~N}$ and another test condition was speed of $60 \mathrm{rpm}$ and load of $10 \mathrm{~N}$. The friction results difference was thought due to accuracy of each tribometers.

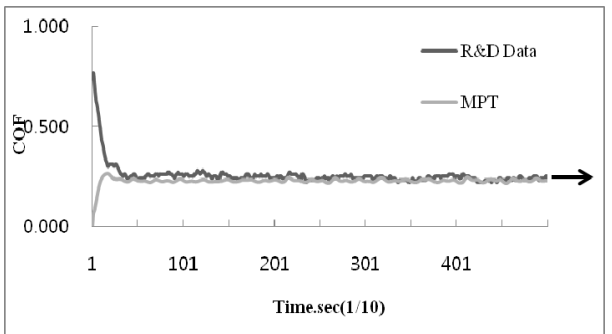

(a) R\&D Pin-on-Disk Test Data

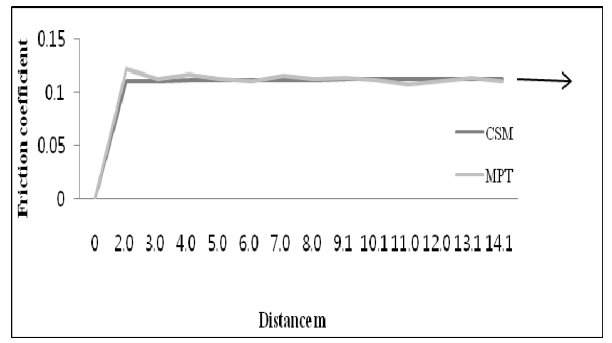

(b) CSM Comparison

Fig. 8. Multi-purpose tester Pin on Disk Test Data

Fig.7 (a) shows the comparison of MPT test results with values from CSM and R\&D for coefficient of friction as function of time. The average difference of $5 \%$ is taking place at the stable condition. Fig. $7 b$ shows comparison of the coefficient of friction as a function of distance between results acquired from well-known CSM tribometer and from MPT, 
both lubricated with oil. The friction coefficient results which were received from CSM Instruments were about 0.11 , while MPT demonstrated 0.13 .

\section{Conclusion}

MPT were designed to measure and evaluate friction and wear through different types of tests using single frame with interchangeable parts. Small MPT was examined through two types of tests: Pin-on-Disk and Thrust bearing tests. Pin-on-Disk test was conducted for the purpose of calibration using the same specimen as a client organization with CSM made tribometer and KOLAS as well. The values of coefficient of friction as a function of distance were determined through CSM by client organization and values of coefficient of friction as a function of time were determined by KOLAS. Thrust bearing test was conducted to verify MPT performance using previous research on UNSM as a basis for comparison. All tests results shown consistency within margin of error. This supports the conclusion that small MPT can be successfully applied to conduct friction and wear tests as designed. Patent of MPT is pending. The work on medium and large versions is in progress.

\section{References}

1. G.S. CHOI, Y.S. PYUN, S.K. HAN, J. H. Park,2010, "A development of the wear and friction test", Korea Society of Machine Tool Engineers pp53

2. Nachman, G., 1999, "Shot Peening-Past, Present, and Future", ASTM Stock Number: MNL56 Proc. 7th Int. Conf. on Shot Peening, pp. 1 4.

3. Kenneth G. Budinski,2007, "Guide to friction, wear, and Erosion Testing", Identification of Different Types of Wear No1,pp1 15

4. Y.S.PYUN, 2005,"CAE S/W Mechanical Design "

5. ISO (2004), "Fine ceramics (advanced ceramics, advanced technical ceramics) -Determination of friction and wear characteristics of monolithic ceramics by ball-on-disc method : 208008"

6. ASTM (2005), "Standard Test Method for Wear Testing with a Pin-on-Disk Apparatus : G99-05"

7. ASTM (2009), "Standard Test Method for Wear Rate and Coefficient of Friction of Materials in Self-Lubricated Rubbing Contact Using a Thrust Washer Testing Machine : D3702-94"

8. ASTM (1997), "Standard Guide for Evaluating Computerized Data Acquisition Systems Used to Acquire Data from Universal Testing Machines : E1856-97" 